\title{
System for studying the parameters of gas solenoid valves
}

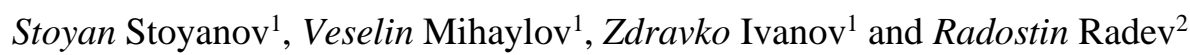 \\ 1 - Technical University of Varna, Department “Transport Engineering and Technologies”, 9010, 1 Studentska Street, Varna, Bulgaria \\ 2 - Technical University of Varna, Department of Automation, 9010, 1 Studentska Street, Varna, Bulgaria \\ Corresponding author contact: s.stoyanov@tu-varna.bg
}

\begin{abstract}
The aim of the present work is to construct a test stand for determining the characteristics of different fourth generation gas injectors working under various conditions as close as possible to the actual operating ones. For this purpose, the standard fourth generation gas system and liquefied petroleum gas (LPG) as a working fluid were used for the stand. A system has been developed to maintain the gas leakage pressure equal in value to the pressure in the intake manifold of a Spark Ignition (SI) engine. Used LPG is compressed and liquefied for reuse. Additionally, safety measures are taken. The stand provides the right conditions for determining the influence of the nozzle diameter, the length of the connecting pipe between the injector and the intake manifold, the differential pressure upstream and downstream of the injector and other factors that affect these characteristics, which may be different when installing LPG system to an internal combustion engine.
\end{abstract}

Keywords: Test stand, LPG injectors, gas fuel, real working conditions.

\section{$1 \quad$ Introduction}

Since the creation of internal combustion engines, researchers have been looking for an appropriate fuel for them. Over the years, the word "appropriate" has had different meanings. While in the beginning there was a demand for fuel with high energy density, low price, easy production and storage, nowadays attention is paid to the environmental impact of the fuel, which makes researchers continue to be interested in alternative fuels and to look for ways to use them effectively.

For the present, LPG remains the most popular alternative fuel (Paczuski, 2016). Its main advantages are lower emissions, good energy density, efficient combustion characteristics, high octane rating (Morganti, 2013), higher knock resistance, low energy price and many others.

LPG is usually used in SI engines as a replacement for base fuel (Pradeep, 2016; Sulaiman, 2013); in diesel engines as dual fuel (Kostadinov, 2016; Qi, 2016; Nemoianu, 2017; Nugroho, 2014; Bogdanov, 2021), where diesel injection is used only to initiate ignition; modified diesel engines with mechanically lowered compression and added ignition system. Although being the most expensive one, the latter usage provides better thermal efficiency due to the higher compression ratio.

LPG fuel is delivered to the engine manifold either in liquid or gaseous phase. One shortcoming of gaseous fuels is power loss (around 4-5\%) due to lower volumetric efficiency (Sunwoo, 1999). LPG liquid phase injection could increase the volumetric efficiency but requires complex and expensive parts.

Nowadays the preferred LPG supply systems for engines are the fourth-generation systems, due to its reliable construction, low cost and easy installation in the existing engines. In these systems, the fuel is delivered to the engine's intake manifold in the gaseous phase by gas injectors (Raslavičius, 2014; Ivanov, 2014).

When building and setting up such systems or when doing simulation research, the flow characteristics of injectors must be known. The manufacturers usually provide the volumetric flow rate (in $\mathrm{nl} / \mathrm{h}$ ) at a given pressure, usually 2 bar, and using air as test medium (Valtek type 30 injector rail. Technical specifications). There is significant difference in the density of vapor LPG and air.

To determine the characteristics of gas injectors in his study (Szpica, 2018) uses a dynamic method that is compatible with the standard JIS B 8390 and involves measuring the pressure in a tank with a 
known volume. For safety reasons, air was used in the experiments. In another study, the same author (Szpica, 2020a) summarized existing methods for determining the characteristics of gas injectors.

The flow characteristics of injectors can be predicted by use of analytical or empirical analysis, or computational fluid dynamics (CFD) simulation software (Ivanov, 2019; Szpica, 2020b; AndrychZalewska, 2020). Using CFD provides an advantage of deeper insight into fluid flow. It should be noted that the use of CFD simulation software cannot replace physical testing and verification should be performed. It is, however, necessary to adjust the parameters of the model in accordance with the experimental results.

It is important to know characteristics of LPG injectors at conditions, as close as possible to the real ones. At the same time, it is important to determine them with the working fluid that is used in the engine. The present paper describes a stand for determining the characteristics of different fourth generation gas injectors under various conditions, as close to the operating ones as possible. For this purpose, the standard fourth generation gas system and LPG as a working fluid were used in the stand.

\section{Gas fuel supply systems for Internal Combustion Engines (ICE)}

\subsection{Current gas injection systems}

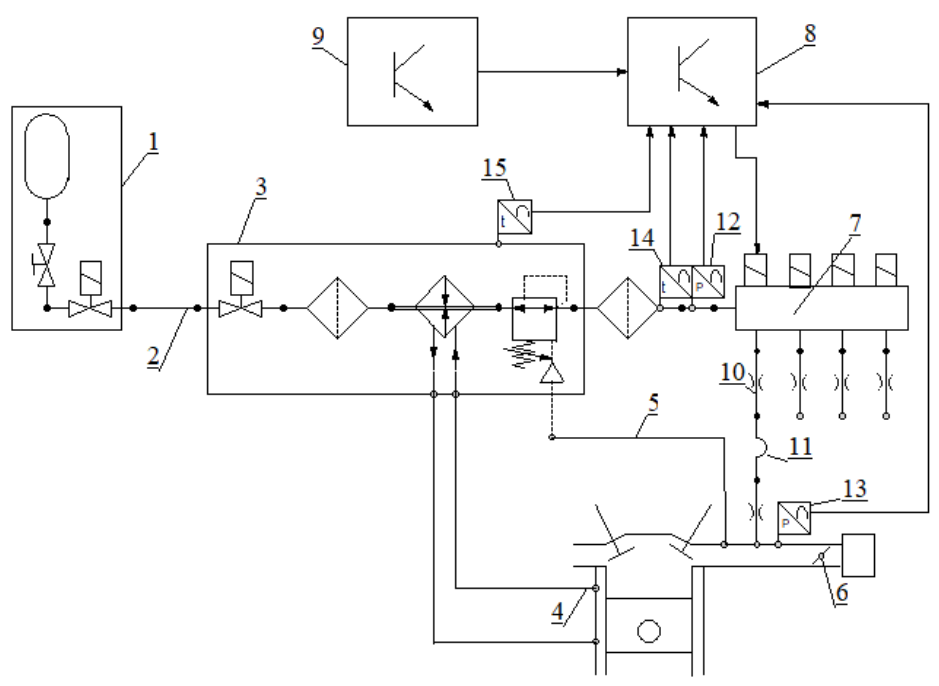

Fig. 1. Fourth generation gas fuel supply systems (description in the main text)

Figure 1 presents a simplified diagram of fourth generation gas supply systems. LPG is stored in a tank 1 in the liquid phase, from which it is delivered to gas pressure regulator 3 via pipeline 2 . The main task of the gas pressure regulator is to maintain a stable differential pressure at the inlet and outlet of the LPG injectors 7 and to change LPG state from liquid to vapor state in a process of adiabatic expansion. The transition from liquid to gaseous state is an endothermic process and the required amount of heat is provided by the engine cooling system 4 . The constant differential pressure is provided from connection 5 between the reducer and the intake manifold of the engine. In most cases, a throttle valve 6 mounted at the inlet of the intake manifold controls SI engine. This valve regulates the amount of air entering the engine, to which the required amount of fuel is added with the injectors. When the throttle is closed and the engine running at idle speed, the pressure in the intake manifold is about $300 \mathrm{mbar}(\mathrm{a})$ (in the paper, "mbar(a)" stands for unit of absolute pressure). This pressure can reach ambient pressure when the throttle is fully open. If the differential pressure maintained by the reducer is $1000 \mathrm{mbar}$, the gas pressure in front of the LPG injector will vary between 1300 and $2000 \mathrm{mbar}(\mathrm{a})$. The number of gas injectors is equal to the number of engine cylinders and injects the fuel near the intake valves. The gas ECU 8 which uses 
petrol injector control signals from the engine ECU 9 controls these gas injectors. This means that the gas ECU only recalculates petrol injector's signals from the original ECU into appropriate signals for the LPG injectors (Mihaylov, 2021). In addition to the shape of the control signal, the gas ECU changes its duration depending on the thermodynamic state of the gas. Information about this condition is obtained from the pressure sensor 12 and from the temperature sensor 14. The sensor 13 measures the absolute pressure in the intake manifold, and the sensor 15 measures the temperature of the reducer. Figure 1 also shows the nozzle 10 and the pipe 11. The diameter of this nozzle and the length of the pipe are selected individually when installing the LPG system to the engine. Apart from factors such as gas pressure and temperature, as well as the duration of the control signal, the cyclic portion of gas also depends on these elements.

\subsection{Gaseous fuel flow}

When a pressure difference occurs between two vessels connected through the smaller cross-sectional area, for example a nozzle, and filled with gas, the gas will pass from the vessel with higher pressure to the vessel with lower pressure. If the gas in higher-pressure vessel has a constant temperature $T_{1}$ and pressure $P_{1}$, the amount of gas passing through the nozzle will depend on the pressure $P_{2}$ of the vessel in which the gas flows. When the pressure difference is small, the gas flow rate will also be small. If increasing the difference between the two vessels, i.e., as the pressure in the second vessel decreases, the velocity of the gas will increase until its velocity reaches the local sound velocity. From this point on, the gas velocity will remain constant and will not increase further, although the pressure in the second vessel continues to decrease. The pressure at which this occurs is called critical pressure $P_{c}$ and its value can be calculated from the dimensionless critical pressure ratio equation.

$$
\begin{gathered}
P_{c}=P_{1} \cdot \beta_{c} \\
\beta_{c}=\left(\frac{2}{k+1}\right)^{\frac{k}{k-1}}
\end{gathered}
$$

where $\mathrm{k}$ is the heat capacity ratio, $\mathrm{P}_{\mathrm{c}}$ is the critical pressure and $\mathrm{P}_{1}$ is the upstream pressure

$$
k=\frac{C_{p}}{C_{v}}
$$

$\mathrm{C}_{\mathrm{p}}$ - specific heat capacity at constant pressure, $\mathrm{C}_{\mathrm{v}}$ - specific heat capacity at constant volume

Table 1. Heat capacity ratio of different gases (Engineering ToolBox, 2003)

\begin{tabular}{|c|c|}
\hline Gas & Ratio of specific heat $-\mathbf{k}-$ \\
\hline Air, Standard & 1,4 \\
\hline N-butane & 1,18 \\
\hline Iso-butane & 1,19 \\
\hline Propane & 1,13 \\
\hline Natural Gas (Methane) & 1,32 \\
\hline
\end{tabular}

Except for transient modes of operation of the engines, the leakage of gas from the injectors is always critical (Ivanov, 2019) and depends on the pressure $P_{1}$ and density $\rho_{1}$ of the gas at the inlet of the injector, from the cross-section area A of the nozzle and from the type of gas used, according to the following relation:

$$
\dot{m}=C_{d} \cdot A \cdot \sqrt{k \cdot \rho_{1} \cdot P_{1} \cdot\left(\frac{2}{k+1}\right)^{\frac{k+1}{k-1}}}
$$


where $\dot{m}$ - mass flow rate $[\mathrm{kg} / \mathrm{s}], \mathrm{C}_{\mathrm{d}}$ - discharge coefficient reflecting the influence of the injector construction.

Additionally, LPG is a mixture of several gases (mainly propane and butane) in different proportions depending on the season and the country in which they are sold. (Paczuski, 2016)

To determine the actual flow characteristics of gas injectors and to avoid mathematical operations to equate the used gases with the characteristics of LPG and influence of discharge coefficient, the experimental conditions should be as close as possible to the real ones and LPG sold at gas stations should be used.

The aim of the present work is to construct a stand for determining the flow characteristics of different types of gas injectors under conditions that are as close to the operating conditions as possible.

The stand provides the right conditions for determining the influence of the nozzle diameter, the length of the connecting pipe between the injector and the intake manifold, the differential pressure upstream and downstream of the injector and other factors that affect these characteristics, which may be different when installing LPG system to an internal combustion engine.

The stand must meet the following conditions:

- Use a weighting method to determine the amount of LPG

- Use LPG sold at gas stations as a working fluid in the stand

- Use a standard fourth generation LPG system

- Ensure that the gas leakage pressure is equal in value to the pressure in the intake manifold of an internal combustion engine

- The used LPG should be compressed and liquefied in an additional tank for reuse.

- Take the necessary measures for maximum safety when using the stand

\section{Test stand for determination of LPG valves characteristics under simulated real working conditions with gaseous fuel}

\subsection{Pneumatic part of the test rig}

Figure 2 makes a broad outline of the pneumatic part of the stand. The gas tank 1 is placed on an electronic scale 2. Through the manual valve 3 and solenoid valve 4, the gas is delivered to the LPG reducer 6 through a flexible pipe 5. With the water pump 7 through the LPG reducer circulates water, which is heated in an electric boiler 8 to different temperature, depending on the needs of the experiment. The evaporated fuel is delivered to the tested injector 11 through filter 9 and an additional heater 10 . Nozzles 12 of different sizes are mounted at the outlet of the gas injector. Immediately after the nozzle an absolute pressure sensor 13 is connected. Through pipe 14, the injector is connected to a nozzle 15 . Apart from the tank, measurement system and the water heating system, the part of the stand discussed so far is a standard LPG system of the fourth generation available on the market. In the next part, a tank 16 with a volume of 20 liters is used to recreate the gas outlet pressure similar to that in an internal combustion engine. An absolute pressure of between 300 and 1000 mbar(a) is maintained inside the tank, which is the pressure in the intake manifold of a SI engine. The tank is also connected to the control chamber of the LPG reducer to maintain the constant differential pressure upstream and downstream of the injector. 


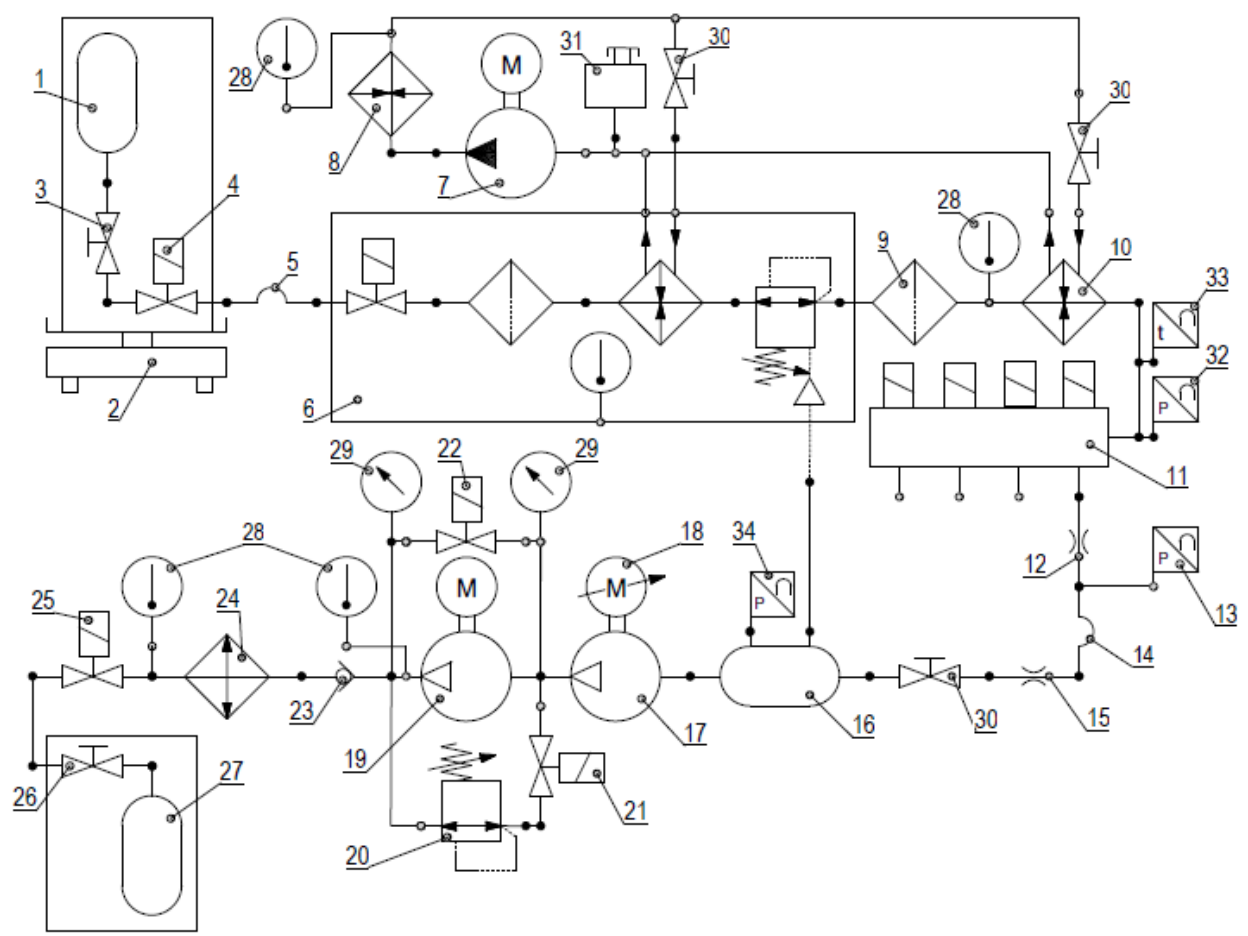

Fig. 2. Pneumatic part of the test rig (description in the main text)

To achieve and maintain this pressure during the measurement, three-piston double-acting compressor 17 from a car air conditioning system is used with a total volume of 150 cubic centimeters per revolution. The compressor is driven by a belt drive of an asynchronous electric motor 18, with the set value of the pressure being achieved by changing its rpm. The use of a car air conditioning compressor to work with flammable gases is not new. For example (Shrivastava, 2016) used a similar compressor in his study using propane. Preliminary tests have shown that the compression ratio of the used compressor is not sufficient to achieve LPG vapor pressure, especially at low inlet pressure values. For this reason, a single-piston compressor 19 with a volume of 9.6 cubic centimeters and constant rpm is connected to the outlet of the first compressor. This compressor is designed to work with butane (R600a) and is used for refrigerators. Throughout the study of different injectors and under different conditions, the gas flow through compressor 17 is kept different at each time. For normal operation of the test stand, it is necessary to provide a constant inlet pressure of compressor 19. The modified standard LPG reducer 20 completes this task when the maintained value is set to 3.5 bar absolute pressure. The modification consists in replacing the adjusting spring with a spring with greater stiffness. The reducer is set so that if the pressure between the two compressors falls below the set value, it connects the outlet of the compressor 19 to its inlet. If necessary, this reducer can be insulated with the solenoid valve 21. Apart from this reducer and its solenoid valve, the solenoid valve 22 makes a direct connection between the outlet and the inlet of compressor 19. It is necessary for this valve to be powered during the compressor startup phase by a button on the control panel in view of the low starting torque of the electric motor driving the compressor. The non-return valve 23 prevents the passage of a large amount of compressed gas to the inlet of the compressor. Compressed to saturated vapor pressure LPG passes through the condenser 24 , the valves 25 and 26 and enters the tank 27. Figure 2 also shows thermometers 28 and manometers 29 mounted at different points to monitor the operation of the stand, valves 30 for controlling the heating of the reducer and isolating the tank 16, as well as an expansion tank 31. The electronic pressure sensor 32 and temperature sensor 33, together with the sensor 13 are connected to a data recording system for further processing of the results. 


\subsection{Control part of the test rig}

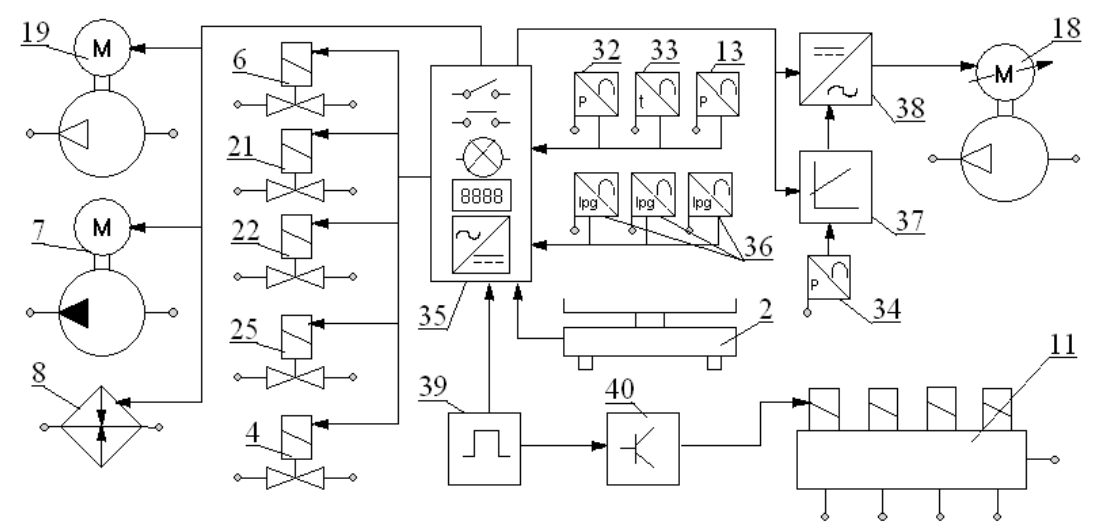

Fig. 3. Control part of the test rig (description in the main text)

Figure 3 shows the control part of the stand. The numbers of the elements that participate simultaneously in the current block diagram and diagram 2 are the same. At this stage, all elements of the stand are controlled independently, and the corresponding electric switches, buttons and indicators are mounted on control panel 35. A procedure has been developed for the sequence of on/off switching of the individual elements. The temperature of the heater 8 is controlled by an IDPlus 961 controller. A gas leak detection system is installed on the stand. This system consists of three separate gas sensors 36 (two MQ-6 and one MQ-2) mounted at specific locations in the gas section of the stand, as well as light and sound signaling on the control panel. The system shuts off the stand in the event of a gas leak. The pressure in tank 16 (Fig. 2) is measured by an absolute pressure transmitter 34 model 266 AST - ABB. The information is transmitted to controller 37 - Comeco RT484, which controls the frequency inverter 38 - Siemens Micromaster 420. The gas injectors 11 are controlled by a standard gas electronic unit 40 made by Fobos Gas. The choice of this controller is dictated by the fact that all corrections to the duration of the control signal to the injector can be switched off. In this way, the duration of the output signal is equal to the duration of the input signal, which is set by a pulse generator 39 and is capable of changing the pulse duration and signal frequency. In addition to the gas ECU, the control signal is fed to the scale controller based on the ATmega328P microcontroller to calculate the mass flow rate per cycle (mg/cycle).

\section{Safety measures}

In addition to the standard requirements for handling flammable gases, regulated in the legislation and good safety practice (UNEP \& WLPGA, 1998), additional safety measures have been taken for the operation of the stand. A gas leak detection system has been installed. In addition, during the operation of the stand, in each individual experiment, specific points are checked with the help of a manual gas leak detector. The solenoid valves 4 and 25 can be switched off automatically from the gas detection system or manually during the experiment. The total amount of gas present in the stand between these valves includes reducers, compressors, tank 16, condenser and pipelines not exceeding 100 grams. Two identical tanks with a volume of 12 liters were used in the stand, as initially tank 1 was filled with $2 \mathrm{~kg}$ of LPG and tank 27 as well as the rest of the pneumatic parts were vacuumed. In addition to the convenience of exchanging the tanks when tank 1 is emptied, this requirement is also related to preventing the risk of overfilling of tank 27 above the permissible $80 \%$ of the volume. 


\section{$5 \quad$ Results and discussions}

During the preparation of the stand at various stages of its construction, several tests were performed to assess its ability to meet the specified conditions. The purpose of the first experiment is to evaluate the performance of compressor 17 whether it can reach the lowest operating pressure of the set point of 300 mbar(a) at the largest amount of gas coming from the gas injector. At this pressure, the compressor capacity must be sufficiently higher than that of the injector. The experiment was performed using air instead of LPG and a Valtek Type-30 gas injector with a nozzle diameter of $3 \mathrm{~mm}$. The differential pressure maintained by reducer 6 is 1000 mbar and the initial pressure in tank 16 is atmospheric pressure (1010 mbar(a)). During the experiment, the gas injector is constantly open, and the compressor is running at maximum speed. The data obtained from the experiment is visually displayed in the graph in Fig. 4.

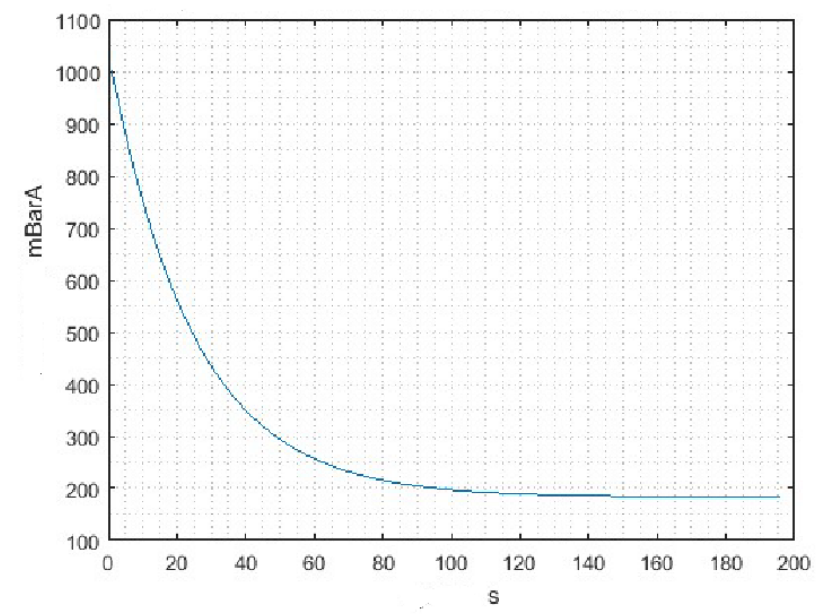

Fig. 4. Pressure changes in the tank at maximum injector flow rate and maximum compressor speed

The minimum pressure reached in this experiment is 183 mbar(a) for about 150 seconds, which is lower than the minimum set point of $300 \mathrm{mbar}(\mathrm{a})$ and it follows that both the compressor and electric motor applied in the study have been appropriately selected.

The purpose of the second experiment is to evaluate the performance of compressor 19. For this purpose, LPG is supplied to the compressor inlet by a gas injector with different duration of the control signal at a differential pressure of 1 bar. Reducer 20 is set to maintain 3.5 bar(a) at the compressor inlet. The initial preparation of the experiment is associated with vacuuming the pneumatic part of the stand and filling it with LPG to a pressure of 3.5 bar(a). A gas leak test was performed using a manual gas leak tester. After switching on the gas leak detection system, the compressor is switched on and the manometers 29 monitor the pressure at its inlet and outlet. Additionally, the compressor temperature and the gas temperature at the compressor outlet and at the condenser outlet are monitored. At various time intervals, the injector is switched on for periods of 10 to 300 seconds with a frequency equivalent to $3000 \mathrm{rpm}$ of the ICE and control signal duration of 5 to $20 \mathrm{~ms}$. As the meters are not connected to recording equipment, the results are recorded manually and are as follows:

- ambient temperature $-17^{\circ} \mathrm{C}$

- LPG temperature $-20^{\circ} \mathrm{C}$

- nozzle diameter $-2,4 \mathrm{~mm}$

- gas injector - Valtek Type-30, 3 ohms

- the total time of the experiment - 15 minutes 
During the experiment, the amount of gas used was $640 \mathrm{~g}$. The maximum temperature at the outlet of the compressor during the duration of the experiment 300 seconds reached $73{ }^{\circ} \mathrm{C}$ and at the outlet of the condenser $18{ }^{\circ} \mathrm{C}$. Gas pressure at the compressor outlet - 10 bar. The experiment showed stable operation of the compressor and the system for maintaining the pressure at its inlet. The gas leak tests did not detect any leaks.

In the next test, the joint work of the two stages of the stand was checked. Thereupon, all elements of the pneumatic part of the stand were connected according to Fig.2. A series of tests were performed at different set pressure in tank 16 and different duration of the control signal to the gas injector. The total amount of LPG consumed in this test was 827 grams.

The final design of the stand and its applicability in determining the characteristics of different LPG injectors under different conditions will soon be forthcoming.

\section{Conclusion}

The paper introduces a test stand for determining the characteristics of fourth generation gas injectors under various conditions that are as close to the operating conditions as possible. One of the distinguishing features of the test stand is that it uses LPG as the working fluid. From the tests conducted on the stand it can be concluded that the system is operational and fulfils the set conditions. Based on the results obtained during the experiments, an appropriate methodology for safe and correct use of the stand has been developed. Established, accordingly, is the required sequence for setting up the system, the on/off switching of the individual elements and the proper safe procedure for exchanging the two LPG tanks.

\section{Acknowledgments}

The research, the results of which are presented in this publication, is part of a project under TU-Varna-based research activities funded by the state budget.

\section{References}

Andrych-Zalewska, M. (2020). Simulation tests of selected gas flow parameters through combustion engine valves. Combustion Engines, 183(4), 21-28. https://doi.org/10.19206/CE-2020-404

Bogdanov, K., \& Hristov, R. (2021). Comparative analysis of the working process of diesel internal combustion engine operating with added CNG and LPG. AIP Conference Proceedings, 2439, 020006 (2021). https://doi.org/10.1063/5.0069138

Ivanov, Z., Stoyanov, S., Mihaylov, V., \& Santos, H. (2019). Flow characteristics of gas injectors. IOP Conf. Ser.: Mater. Sci. Eng., 664, 012021. https://doi.org/10.1088/1757-899X/664/1/012021

Ivanov, Z., Mihaylov, V., \& Mersinkov, H. (2014). Optical method for measurement needle lift of electromagnetic valves for LPG/CNG injection, Proc. of Int. Sci. Conf. EKO Varna -2016, 21, 415-422, ISSN 2367-6299, (in Bulgarian)

Kostadinov, D., \& Bogdanov, K., (2016). Methods of providing gaseous fuel in diesel engines. Proc. of University of Ruse -2016, 55(4), 106-109. (in Bulgarian)

Mihaylov, V., Ivanov, Z., Mersinkov, H., Stoyanov, S., \& Wrobel, R. (2021). Influence of the control signal on parameters of low impedance injectors for SI engines. IOP Conf. Ser.: Mater. Sci. Eng., 1031, 012018. https://doi.org/10.1088/1757-899x/1031/1/012018 
Morganti, K., Foong, T., Brear, M., Silva, G., Yang, Y., \& Dryer, F. (2013). The research and motor octane numbers of Liquefied Petroleum Gas (LPG). Fuel, 108, 797-811. https://doi.org/10.1016/j.fuel.2013.01.072

Nemoianu, L., Pana, K., Negurescu, N., Cernat, A., Fuiorescu, D., \& Nutu, C., (2017). Study of the cycle variability at an automotive diesel engine fuelled with LPG. MATEC Web Conf., 112 (2017) 10006, https://doi.org/10.1051/matecconf/201711210006

Nugroho, A., Sinaga, N., \& Haryanto, I., (2014). Performance of a compression ignition engine four strokes four cylinders on dual fuel (diesel-LPG). AIP Conference Proceedings, 2014, 020166 (2018) https://doi.org/10.1063/1.5054570

Paczuski, M., Marchwiany, M., Puławski, R., Pankowski, A., Kurpiel, K., \& Przedlacki, M. (2016). Liquefied Petroleum Gas (LPG) as a Fuel for Internal Combustion Engines. Alternative Fuels, Technical and Environmental Conditions, Krzysztof Biernat, IntechOpen. https://doi.org/10.5772/61736

Pradeep, J., \& Porpatham, E. (2016). LPG gaseous phase electronic port injection on performance, emission and combustion characteristics of Lean Burn SI Engine. IOP Conf. Ser.: Earth Environ. Sci. 40, 012069. https://doi.org/10.1088/1755-1315/40/1/012069

Qi D., Chen, B., \& Zhang, D. (2016). Combustion and Exhaust Emissions Characteristics of a DualFuel Compression Ignition Engine Operated with Diesel Fuel and Liquefied Petroleum Gas. Journal of Energy Engineering, 142(4). https://doi.org/10.1061/(ASCE)EY.19437897.0000359

Raslavičius, L., Keršys, A., Mockus, S., Keršienė, N., \& Starevičius, M. (2014). Liquefied petroleum gas (LPG) as a medium-term option in the transition to sustainable fuels and transport. Renewable and Sustainable Energy Reviews, 32, 513-525. https://doi.org/10.1016/j.rser.2014.01.052.

Shrivastava, A., \& Dahake, M. (2016). Performance Analysis of Automobile Air Conditioning System using Propane (R290). International Research Journal of Engineering and Technology, 3(07), 1344-1347.

Sulaiman, M., Ayob, M.,\& Meran, I., (2013). Performance of Single Cylinder Spark Ignition Engine Fueled by LPG. Procedia Engineering, 53, 579-585. https://doi.org/10.1016/j.proeng.2013.02.074

Sunwoo, M., Sim, H., \& Lee, K. (1999). Design and development of an ECU and its air-fuel ratio control scheme for an LPG engine with a Bypass injector. Proceedings of the IEEE International Vehicle Electronics Conference (IVEC'99), 508 - 513. https://doi.org/10.1109/IVEC.1999.830740

Szpica, D. (2018). The determination of the flow characteristics of a low-pressure vapor-phase injector with a dynamic method. Flow Measurement and Instrumentation, 62, 44-55. https://doi.org/10.1016/j.flowmeasinst.2018.05.010

Szpica, D. (2020a). Determination of low pressure gas injector valve flow factor. Eng. Rural Dev., 2020, 721-729. https://doi.org/10.22616/ERDev.2020.19.TF167 
Szpica, D., Borawski A., Mieczkowski G. (2020b). Numerical determination of low pressure gas injector flow characteristics depending on outlet nozzle diameter. Eng. Rural Dev., 2020, 730 738. https://doi.org/10.22616/ERDev.2020.19.TF169

UNEP, \& WLPGA. (1998). LP Gas Safety: Guidelines for Good Safety Practice in the LP Gas Industry. UNEP/Earthprint. ISBN: 92-807-1711-1

\section{Online sources}

Engineering ToolBox. (2003). Gases - Ratios of Specific Heat. (Date of Access 2021, November 24) Retrieved from https://www.engineeringtoolbox.com/specific-heat-ratio-d_608.html

Valtek type 30 injector rail. Technical Specifications. (Date of Access 2021, November 26) Retrieved from https://www.valtek.it/en/products/injectors/type-30. 